\title{
Desertification Risk and Rural Development in Southern Europe: Permanent Assessment and Implications for Sustainable Land Management and Mitigation Policies
}

\author{
Rosanna Salvia ${ }^{1} \oplus$, Gianluca Egidi ${ }^{2}$, Sabato Vinci ${ }^{3}$ and Luca Salvati ${ }^{4, *}$ \\ 1 Mathematics, Computer Science and Economics Department, University of Basilicata, Viale dell'Ateneo \\ Lucano, I-85100 Potenza, Italy; rosanna.salvia@unibas.it \\ 2 Department of Agricultural and Forestry Sciences (DAFNE), Tuscia University, Via San Camillo de Lellis, \\ I-01100 Viterbo, Italy; egidi.gianluca@unitus.it \\ 3 Department of Political Science, Third University of Rome, Via G. Chiabrera 199, I-00145 Rome, Italy; \\ sabato.vinci@uniroma3.it \\ 4 Council for Agricultural Research and Economics (CREA), Viale S. Margherita 80, I-52100 Arezzo, Italy \\ * Correspondence: luca.salvati@crea.gov.it
}

Received: 1 November 2019; Accepted: 6 December 2019; Published: 11 December 2019

check for updates

\begin{abstract}
The United Nations Convention to Combat Desertification defines 'land degradation' as a reduction or loss of the biological and economic productivity resulting from land-use mismanagement, or a combination of processes, such as soil erosion, deterioration of soil properties, and loss of natural vegetation and biodiversity. Land degradation is hence an interactive process involving multiple factors, among which climate, land-use, economic dynamics and socio-demographic forces play a key role. Especially in the Mediterranean basin, joint biophysical and socioeconomic factors shape the intrinsic level of vulnerability of both natural and agricultural land to degradation. The interplay between biophysical and socioeconomic factors may become extremely complex over time and space, resulting in specific patterns of landscape deterioration. This paper summarizes theoretical expectations and empirical knowledge in the field of soil and landscape degradation in Mediterranean Europe, evidencing the intimate relationship between agriculture and socio-demographic factors of growth (or decline) of rural areas. Understanding spatio-temporal trends of each factor underlying land degradation and the related background context is a key tool in the assessment of the spatial distribution of vulnerable and critical land to degradation. Empirical results of a permanent monitoring of land degradation contributes to delineate more effective conservation policies through identification of target areas requiring specific actions for biodiversity and landscape protection. With increasing human pressure on rural environments, a diachronic evaluation of patterns and processes of land degradation reveals particularly appropriate in a both positive and normative perspective, prefiguring new actions for soil conservation and landscape valorization under global change.
\end{abstract}

Keywords: soil quality; drought; human pressure; rural sociology; Mediterranean region

\section{Introduction}

With globalization, technological and cultural integration among countries and regions have enlarged the role of economic and financial targets when designing criteria of development, production and consumption [1,2]. In advanced economies, breaking down communication boundaries, facilitating trade and allowing access to secondary goods to specific population segments are required actions in most disadvantaged and marginal rural areas [3-5]. Traditional economic frameworks are demonstrated 
to explain the progressive 'cultural standardization' and 'policy convergence' typical of Western societies in a partial way. Being intimately rooted in adaptation processes to demographic, socio-cultural, institutional and environmental contexts, the increase of income and consumption levels in rural districts has shaped mechanisms of land resource exploitation with ecosystem costs that result in environmental degradation and ecological disturbance [6,7]. Thanks to globalization, challenging socioeconomic issues are increasingly dealt with spatially generalized and temporally persistent global warming. According to an evolutionary perspective, climate change-albeit with effects largely varying over space-is reflected into a significant and generalized warming and more sparse alterations in rainfall regimes, with a greater frequency and severity of extreme events, both heavy rainfalls and droughts [8].

Under global change, local communities are more sensitive to the immaterial needs of human well-being and, consequently, to the widespread recognition of damages that derive from an unsustainable socioeconomic development [3-5]. Although awareness of environmental problems is more evident in advanced economies, coordinated strategies at both continental, country and regional scale are required to cope with present (and future) environmental problems, and especially with a progressive degradation of land resources. Regarded as a possible response to counteract land degradation, practical actions oriented toward the holistic notion of 'sustainability' were mainly based on the ability to reconcile livelihood and growth needs of today's society with priorities and limits for the environment $[9,10]$. The concept of "sustainable development" incorporates interlinked factors possibly characterizing the evolutionary dynamics of complex systems. In these regards, research is increasingly required to provide a knowledge base to identification, analysis and interpretation of relevant information dealing with a sustainable rural development [11,12].

Given the amplitude and unpredictability of global change, a multi-dimensional approach to land degradation is necessary to grasp complexity of local systems, involving disciplines from economics to biology, from soil science to sociology, from agronomy to geography, from demography to forest science [13]. In some cases, the urgent need to plan, manage, preserve, develop and recover land in a 'sustainable' way has stimulated innovative approaches to complex systems' thinking, improving rationale, data sources, and analytical techniques. By integrating biophysical and socioeconomic disciplines, the study of land degradation processes is an example of a 'land science' based on substantive knowledge. This emerging discipline encourages a comprehensive investigation of landscapes, identifying the constituting elements of complex systems and classifying them into homogeneous (functional) groups, aggregates or types [14]. A specific approach is presented in Figure 1, defining basic knowledge of 'land degradation' as a mix of trans-disciplinary issues-ranging from the socioeconomic dimensions to a specific component of biodiversity and ecosystem services. The physical environment and the land cover dimension complete the holistic knowledge of land degradation system's complexity, evidencing how identification of best practices that may counteract land degradation, needs specific knowledge based on refined monitoring systems.

By investigating spatio-temporal dynamics that characterize particularly vulnerable environments, such as the Mediterranean basin $[3,4,15]$, the proposed approach is aimed at improving a 'land science' paradigm that may reconnect substantive knowledge with policies. Cultural and social traits, biophysical settings and landscape issues are key components of complex systems experiencing land degradation processes. In these regards, Southern Europe is considered representative of the socio-ecological complexity typical of local contexts affected by land degradation. A refined assessment framework interpreting the intimate complexity of land degradation drivers in such contexts, contribute to more effective design and implementation of mitigation policies adaptable to a vast set of environmental conditions and socioeconomic settings. 


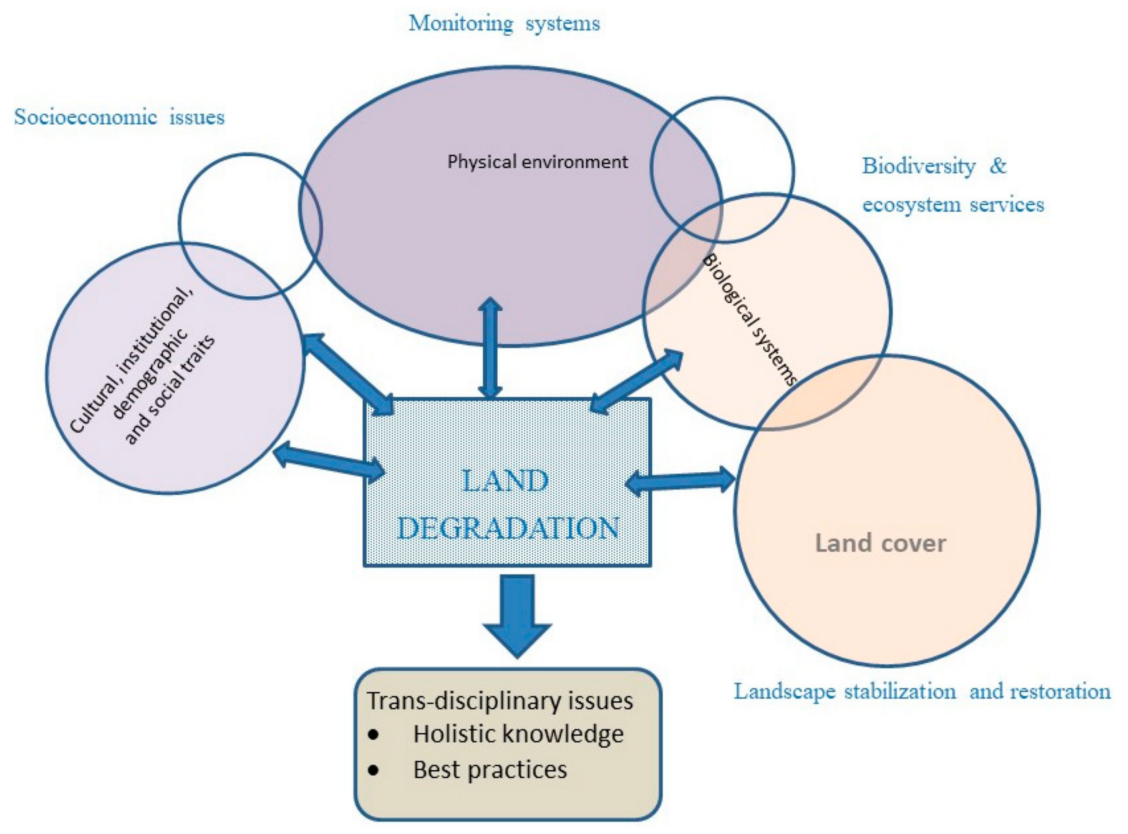

Figure 1. Land degradation due to heavy soil erosion in internal rural areas of Southern Italy (southern Sicily, left; Basilicata, right). Source: authors' own elaboration.

Based on these premises, the present study proposes a brief reflection on the intimate complexity of land degradation processes in Southern Europe, elaborating an integrated framework spanning from operational definitions to permanent assessment, in line with the framework illustrated in Figure 1. By focusing on positive and normative dimensions of sustainability, operational definitions of land degradation and the concept of land vulnerability were reviewed and briefly discussed with specific reference to the Mediterranean region (Section 2). A specific section was devoted to identification of driving forces of land degradation in a Mediterranean socioeconomic context (Section 3). Such discussion contributed to a more integrated interpretation of land degradation complexity grounded on multi-domain indicators of land vulnerability (Section 4). The specific contribution of an integrated assessment to policy definition was debated in Section 5, evidencing the limits of the actual reference frameworks in Section 6. In this regard, a specific policy strategy ('Zero net land degradation') was analyzed in Section 7. An integrated discussion of land degradation complexity from both positive and normative perspectives was finally proposed in Section 8, giving specific suggestions for future theoretical and practical studies.

\section{Operational Definitions}

The United Nations Convention to Combat Desertification (UNCCD)—a legally binding international agreement promoting a sustainable management of land with the aim to reduce the effects of land degradation-has formulated an official definition of desertification within the Article 1, Section A: "soil degradation in arid, semi-arid and dry sub-humid areas attributable to various causes, including climatic variations and human activities". This definition marked a step forward in the fight against land degradation, recognizing the predisposing role of natural factors (e.g., climate change), and the importance of human response to specific environmental problems [16,17]. Anthropogenic impacts due to land-use mismanagement, urbanization and the increasing negative externalities of economic activities, are regarded as relevant forces of land degradation. These drivers have demonstrated to trigger soil sealing, erosion and loss of plant cover, resulting in chemical, physical and biological deterioration of soils [18-21].

Land degradation implies a decrease in one (or more) dimensions of land quality. Desertification is seen as the last stage of land degradation and implies an irreversible loss of the pristine agricultural 
and forest productivity - from both the ecological and the economic point of view [16]. While referring to the physiological expansion of desert-like land, this term is evocative of rapid transformations of the pre-existing environment into a 'deserted wilderness of sand and dunes'. Although such processes are infrequent in advanced economies, land degradation includes temporary and more latent environmental phenomena leading to a decline in landscape quality, with cascading consequences on biodiversity, deterioration of plant cover and, ultimately, soil fertility [14]. Compared with desertification, land degradation processes are not confined to specific ecological environments [17], while being observed across all continents, though more frequently in ecologically fragile and economically marginal areas.

The notion of "land" in the abovementioned definition assumes the specific meaning of a "bio-reproductive system including soil, vegetation and the ecological/hydrological phenomena that are produced within this system". In this way, the concept of "land degradation" implies the decrease (or the complete loss) of biological and (or) economic productivity (Article 1, Sections E-F, 1996). In both advanced and emerging economies, land degradation is more frequently observed in locations with accentuated environmental vulnerability because of arid (or semi-arid) climate and where forms of land exploitation are practiced in a non-sustainable, and possibly unregulated, way [10]. In Europe, the Northern Mediterranean arch is considered a hotspot for land degradation and many areas in the most arid regions of Spain, Southern Italy and insular Greece are now experiencing particularly worse environmental conditions leading to land degradation and an increasing risk of desertification.

\section{Underlying Causes and Effects of Land Degradation in Mediterranean Europe}

In Europe, nearly 97 million hectares of land were classified as affected by soil degradation out of a total of 300 million hectares [17,22]. This evidence has contributed to generate a greater awareness of the spatial extent and severity of land degradation, contributing to correct the erroneous take-home message that only the poorest and economically marginal areas in the world can be affected by processes of land resource depletion. Even in advanced economies, land degradation represents a key problem, sometimes because of climate change, anthropogenic pressure or both [3,5]. At present, countries facing the Mediterranean Sea (Portugal, Spain, Italy, Greece, Albania, Bosnia and Herzegovina, Croatia, Cyprus, France, Malta, Slovenia, Spain and Turkey) are relatively more exposed to land degradation than the remaining European countries. As far as the general level of country's land vulnerability is concerned, about 37 million hectares of land were classified vulnerable due to irreversible degradation processes. Critical land conditions are identified in some specific regions of the abovementioned countries, where the percentage of the threatened land is even higher (Figure 2). Southern Portugal, some districts of Southern Spain and Insular Greece, and the two major islands in Italy, Sardinia and Sicily, are representative examples of these conditions [16].
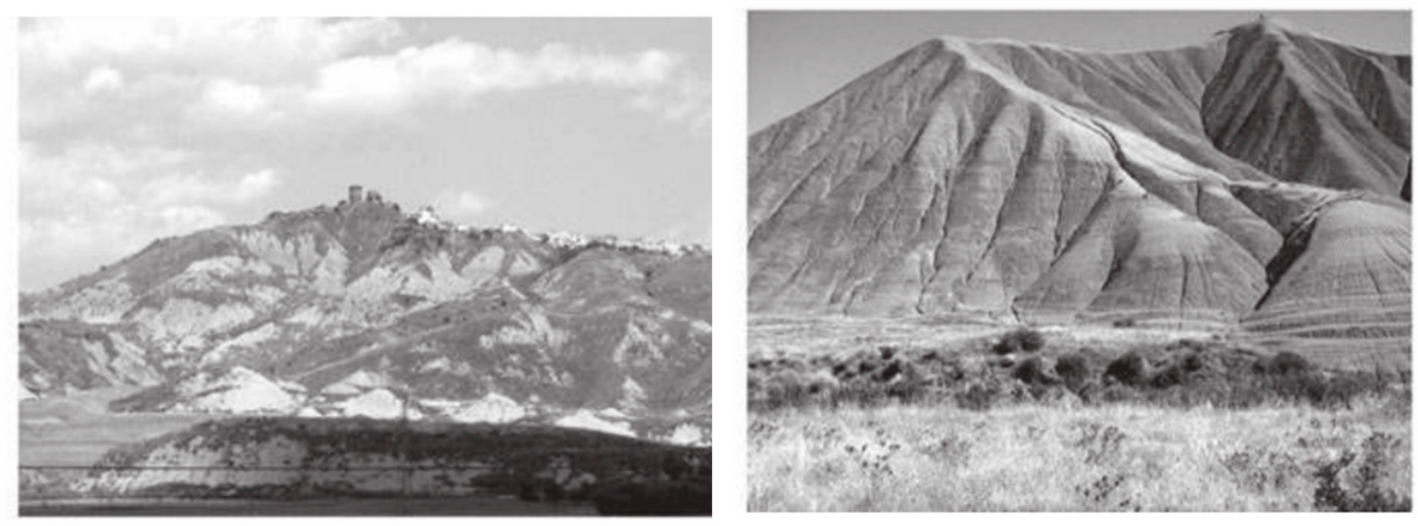

Figure 2. Land degradation due to heavy soil erosion in internal rural areas of Southern Italy (southern Sicily, left; Basilicata, right). Source: authors' photographs. 
In Mediterranean contexts, drivers of land degradation are usually classified as environmental factors and human pressures [22]. Environmental factors include (i) climate regime (dry conditions with low rainfall ranging between 200 and $400 \mathrm{~mm}$ per year may trigger land degradation); (ii) drought, affecting both arid and wet areas, and occurring when precipitations are lower than the normal level of the reference time period; (iii) heavy rainfalls, causing soil erosion; and (iv) topography (steep relief promotes soil erosion and landslides). Depending on the exposure of the slopes, microclimate conditions that are unfavorable to the regeneration of vegetation can be identified as relevant, indirect drivers of land degradation [7]. Soil degradation is also triggered by a progressive physical deterioration and spatial reduction of plant cover. Simplifying vegetation (loss of biodiversity) decreases the protective effect on the soil, until the process becomes irreversible. Even in this case, unsustainable agronomic practices may aggravate local conditions. In this perspective, less-structured soils with low content of clay and organic matter are mostly exposed to physical deterioration. Such components contribute to keep soil particles together, resulting in a micro-porous structure that provide better conditions for roots, micro-flora and micro-fauna of the soil, as well as storage of the soil, water and nutrients. Human pressure also reduces soil quality through an increase of urbanization-driven land imperviousness.

Anthropogenic factors include (i) misuse of water resources (unplanned groundwater exploitation often prevents bog recharge; along the coastal strips, an excessive embankment from the aquifers results in soil contamination because of intrusion of saline wedge; irrigation of brackish water crops causes long-term soil salinization, lowering soil fertility); (ii) agricultural intensification contributing to soil loss due to e.g., water erosion; (iii) deforestation (excessive exploitation of forests and their destruction result in an rapid increase of the soil surface exposed to degradation, resulting in a substantial reduction of soil water retention capacity). In addition, forest cleaning cause much damage than benefits, as they prevent the formation of new humus by eroding soils. Leaving the ground uncovered, wildfires have adverse effects on the structure and content of soil organic matter. Wildfires also form water-repellent substances that accelerate surface water rippling and sediment transport. Moreover, the use of unsuitable agricultural machinery can significantly alter the soil structure by reducing water infiltration capacity, increasing soil erosion and enhancing soil compaction. Heavy and inadequately applied mechanization leading to irregular soil management is a major problem in soil degradation, especially the use of inadequate soil cultivation (e.g., plowing) in agricultural production. For instance, the application of heavy machinery on clay soils and the use of plowing result in soil compaction. This process of soil degradation prevented water infiltration in deeper layers which leads to the stagnation of water in the surface layer [23-25].

The use of unbalanced fertilization that does not provide a proper mix with organic products impoverishes soils that eventually will lose the ability to retain chemical nutrients. In some cases, overgrazing-in addition to the already mentioned degradation of plant cover-may determine a subtle compaction of surface soil layers. Finally, urbanization is perhaps the process with the most immediate and serious effects among those analyzed $[6,18,26]$. The specific contribution to land degradation is direct, due to soil sealing, and indirect, due to destruction of natural resources, interference with the renewal cycle of the same resources, and other land-use impacts [27]. Land exposed to degradation in urban areas are characterized by fragile ecosystems, sensitive to exploitation of natural resources, and requiring specific land protection measures [28-34].

\section{Land Degradation in Mediterranean Europe: The Environmentally Sensitive Areas Approach}

Identification of areas at risk of desertification and a comprehensive knowledge of causes and consequences of land degradation are preliminary steps to implementation of strategies counteracting land depletion [35-37]. To determine the level of land vulnerability to degradation in a given location, a number of indicators have been proposed for the Mediterranean context. Moreover, specific indicators' systems integrating biophysical and socioeconomic dimensions were introduced with the aim to evaluating ecosystem response to environmental disturbance caused by external pressures $[3,5,15,38]$. Indicators of land vulnerability are requested meet specific criteria and, more specifically, (i) readability 
(ability to focus on the specificity of the study area or the intrinsic phenomenon of degradation), (ii) measurability, (iii) relevancy, (iv) availability, and (v) updatability over time [39]. Being grounded on these criteria, the "Environmentally Sensitive Areas" (ESAs) approach is a specific framework for spatially explicit assessment of the level of land vulnerability to degradation in Mediterranean environments. The ESA approach was the developed in the framework of the cooperative MEDALUS (MEditerranean Desertification and Land Use) international research projects financed by European Commission. A standardized index, namely the ESAI (Environmentally Sensitive Areas Index) was also proposed that can be adapted to different input data covering a wealth of diverse environmental and socioeconomic conditions, being applied in several contexts ranging from Portugal to Turkey [31,32]. The ESAI defines a concept of environmental quality depending on specific dimensions (soil, climate, vegetation and land management). These dimensions are quantitatively evaluated using four 'land quality' indicators that are regarded as key drivers of land degradation in the abovementioned regional contexts (Figure 3).

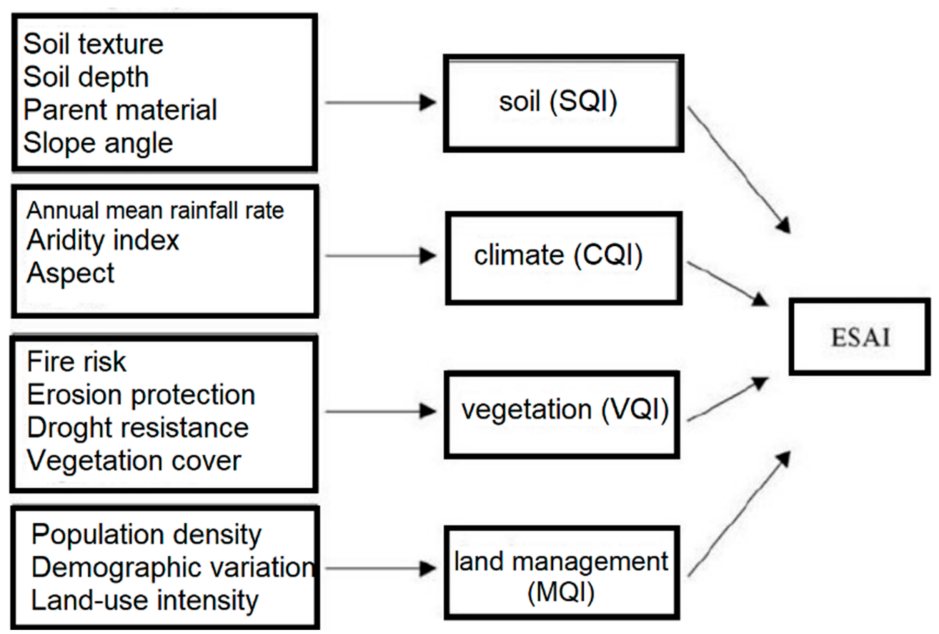

Figure 3. Basic components of specific dimensions of land degradation (soil, climate, vegetation, land management) according to the Environmentally Sensitive Area Index (ESAI) framework. Source: own elaboration.

For each dimension, elementary indicators were chosen to illustrate landscape complexity and the linkage with land degradation. Four partial indices quantifying the contribution of each dimension to the level of land vulnerability at a given location were derived from computation on the respective elementary indicators. Based on a review of earlier studies, a specific score was assigned to each indicator depending on the direct (or indirect) relationship with land degradation. The score system allows the composition of individual indicators into a land quality index ranging from 1 to 2 . The lowest and the highest scores respectively indicate the mildest and the strongest contribution to the overall level of land vulnerability to degradation at a given location. The final ESAI, a composite index ranging from 1 (the lowest level of land vulnerability to degradation) to 2 (the highest level of land vulnerability to degradation) was calculated as the geometric mean of the four land quality indicators described above [31]. The ESAI was frequently reclassified into four land types ('critical' land, 'fragile' land, 'potential' land and 'not threatened' land) with the aim to identify different levels of land vulnerability to degradation [31].

An additional contribution to evaluate location and extent of land exposed to degradation in Northern Mediterranean countries was provided by the Desertification Information System to support specific National Action Plans developed under the DISMED Project financed by European Commission. The project has considered three predisposing factors (climate, soil, vegetation) with the aim at providing decision-makers with scientific knowledge useful to improve effective policy measures to counteract the effects of drought and to fight land degradation [8,36]. This objective 
was pursued through the strengthening of international communication, facilitating the exchange of information and establishing a common information system to monitor biophysical and socioeconomic conditions in vulnerable areas, by assessing the extent, severity and progress of land degradation. Results of the program indicate that Spain has the largest vulnerable area $(8.5 \%$ of the country's land affected by a high level of land degradation) followed by Greece, with highly affected land amounting to $5.8 \%$ of the national territory (Figure 4 ). This country has the largest area affected by an intermediate level of desertification risk (36.9\%). Italy's country area has 3.1\% of vulnerable land, and $32.1 \%$ of total land exposed to an intermediate level of land degradation. Based on the empirical results of this assessment, Spain was — on average — the country most affected by land degradation [36].

Despite the extensive use of the ESAI in environmental monitoring, the definition of areas exposed to land degradation and the identification of locations where the level of land vulnerability has increased over time, requires the joint use of biophysical indicators and variables assessing human-induced pressure and ecological disturbances. Depending on the precise type of land management, land resources are used in many forms-more (or less) compatible with ecosystem equilibrium. Additional frameworks were proposed in different cooperative research projects and community initiatives, for instance, Sustainable Agriculture and Soil Conservation (SoCo), Preventing and Remediating degradation of soils in Europe through Land Care (RECARE), and more generally, the European soil monitoring and assessment framework. In this regard, a spatially explicit land management program calls into question a set of environmental and socioeconomic factors and the related indicators informing a sustainable land management strategy should account for complex phenomena and contexts. For instance, land abandonment depending on a polarized economic development in dynamic urban areas and marginal rural districts, has led to both soil deterioration or improvement depending on pristine soil type and climate conditions and the local background context [40-42]. In this regard, the adoption of measures promoting soil conservation was demonstrated to mitigate the environmental impact of land mismanagement [43], at least where the environmental and socioeconomic context is responsive to such measures [44].

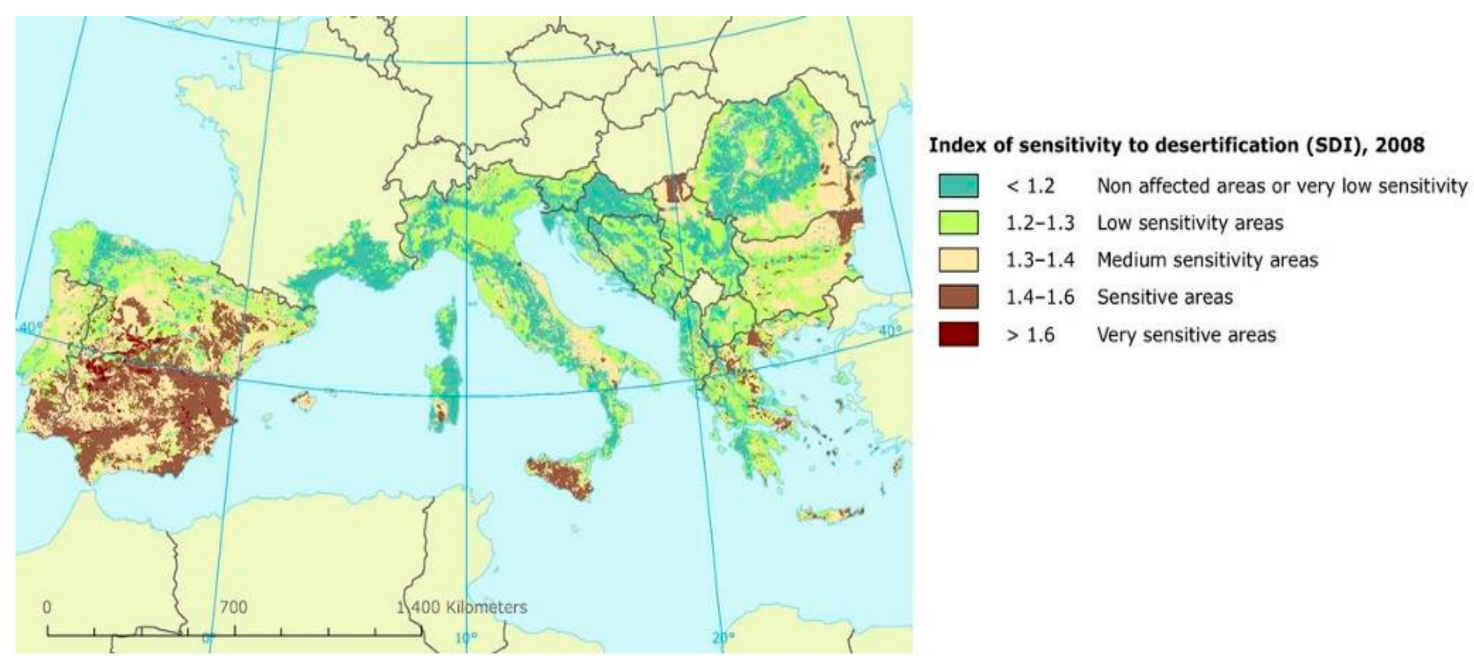

Figure 4. A map of the level of vulnerability to land degradation based on the SDI index in selected European countries. Source: DISMED project.

\section{Research and Policies}

Land degradation - together with climate change and biodiversity loss - is one of the biggest challenges for sustainable development, recognized since the summit of Rio de Janeiro in 1992. The UNCCD was set up in 1994 and, actually, 196 countries participate to the Convention. In the context of an integrated approach compatible with the Agenda 21 program, the UNCCD identified the "international cooperation and partnership agreements" as an indispensable tool for establishing 
sustainable development in affected areas (Article 2.1). International cooperation makes possible to coordinate data collection, analysis and exchange, to prevent (or mitigate) environmental and social damages resulting from on-going land degradation processes, to restore soil productivity, to contain the negative effect of drought, to improve living conditions in dryland, and to combat poverty promoting environmental sustainability at the same time $[39,45]$. To reinforce this participative approach, the UNCCD actively cooperate with other two conventions, the Convention on Biological Diversity (CBD) and the United Nations Framework Convention on Climate Change (UNFCCC).

Many countries in the Mediterranean basin are part of the UNCCD under Annex IV, a specific annex dealing with Mediterranean countries. This annex includes Albania, Bosnia and Herzegovina, Croatia, Cyprus, France, Greece, Italy, Malta, Portugal, San Marino, Slovenia, Spain and Turkey [39]. The UNCCD convention has produced guidelines on identification and use of pertinent indicators monitoring land vulnerability in Mediterranean environments [41,42,46]. These indicators are based on available data sources in the different participant countries, including satellite imagery, topographic data, climatic and geological data, land-use and population maps reflecting the impact of socioeconomic aspects [32]. The countries of Annex IV for the North Mediterranean basin intend to fulfill the objectives of the Convention basically with land planning and active intervention of soil recovery. At the same time, the European Union has supported the fight against land degradation through provision of technical information and data (and especially high-quality, geo-referenced data) through the institutional activity of the European Environment Agency, research and monitoring activities at Joint Research Centre of Ispra (Italy), results and practical tools from international programs and cooperative research projects, and other specific measures [20]. However, the Thematic Strategy for Soil Protection remains the only direct institutional response to land degradation, since land planning is basically considered an issue of national competence. In these regards, requirements comprised in horizontal and sectoral policies provide tools to address land degradation at national and subnational scales [47].

The joint activity of the Mediterranean countries within the European Commission aims to redirect the interests of the Commission to the problems of land degradation in different areas and regions. For instance, agro-forestry and hydro-geological resource utilization programs are examples of indirect tools mitigating land degradation under specific local contexts [16,22]. However, local communities in vulnerable regions remain the largest cultural resource on which to base the integrated struggle against the progressive degradation of any given territory $[14,17]$. In these regards, reports and guidelines elaborated on behalf of the national Committees for Fighting against Desertification in Annex IV countries, and the resulting regional/local plans to combat desertification risk, identify strategies and objectives that stimulate and re-orient environmental policies against land degradation $[36,43]$.

More specifically, National Action Plans provide the interpretative base for spatial land management and dedicated guidelines to implement policies reducing land degradation in the context of a sustainable rural development. For instance, a permanent system of environmental monitoring of land ecosystems was established in the Italian National Action Plan with the aim to promote the contribution of grassroots communities by stimulating the active participation of relevant local authorities and individual stakeholders (e.g., farm holders, researchers, planners, architects and other technical professionals) [17]. In this perspective, the Italian national plan was oriented toward policies promoting a fine-tuning between the impact of productive activities, especially agriculture, and a high degree of environmental protection, in turn avoiding depopulation and land abandonment of internal areas $(14,40)$.

The complex articulation of the Italian national plan in regional direction plans and specific local action plans, highlights how this planning strategy allows policy flexibility at different intervention scales. Guidelines are provided on a national scale, considering general phenomena of land degradation both in highly vulnerable contexts, such as southern Italy, and in less critical contexts, such as Northern Italy, that could shift into worse environmental conditions in a few years, thanks to climate change. On a regional scale, practical actions are identified to deal with specific degradation phenomena-well known as a result of extensive monitoring (also through the integrated system of ESA indicators. 
These actions were defined on the base of the environmental and socioeconomic characteristics of affected districts. Dedicated interventions are outlined for land at high naturalistic value, for economically depressed and marginal districts, for areas experiencing agricultural intensification.

These interventions are fully integrated into an integrated policy framework, which also considers other rural development interventions and the improvement of socioeconomic conditions. Specific actions are promoted to reinforce (or counteract) the specific effects of rural development policies. For instance, with the European Common Agricultural Policy (CAP), farmers were stimulated to reach a higher production efficiency and the consequent land-use change, thanks to transformations in cropping practices and the socioeconomic profile of local communities, added to the progressive abandonment of marginal areas, altering the composition and structure of rural landscapes [48]. Agro-environmental measures and other specific interventions mitigating the negative impact of landscape transformations are discussed and proposed in specific contexts, reconnecting the 'regional' dimension with a more detailed, 'local' dimension of intervention. Finally, the local plans represent a sort of fine tuning between the regional measures, coordinated with the national measures and fully consistent with European guidelines and the operational framework adopted on a supra-national scale (e.g., UNCCD), and the specific actions on the territory. These interventions have required a fine tuning with the characteristics and demands of local communities, which represent the crucial element that may determine the success (or failure) of each specific local strategy against land degradation.

Based on these premises, an effective strategy containing land degradation should promote a global effort to reconcile development and environmental protection by privileging the community's right to (socially balanced and environmentally sustainable) land-use and quality of life, in the light of a true 'zero net' land degradation vision in the affected territories. Such a strategy may include projects advancing young education and societal awareness of environmental issues, e.g., incorporating key topics such as conservation of land resources in school education. This can be due in relation to the environmental and cultural realities existing in the area, but also taking account of slow (or latent) changes in unsustainable macro-patterns and individual behaviors that may enhance land degradation. These policies can be effectively implemented only if accompanied by appropriate social initiatives that promote the permanence of rural communities, contrasting depopulation and land abandonment. Based on this strategy, creating an integrated system of environmental monitoring and support for decisions in vulnerable environments is particularly relevant and demanding [10,41,46,49]. A better coordination of permanent monitoring and planning tools depends on the emphasis on sustainable development in rural contexts [50,51]. A sustainable rural development is together a pre-requisite and a key process guiding more effective mitigation strategies.

\section{The Limits of Reference Frameworks}

In rural areas of the Mediterranean region, land capability to agriculture, pasture and forestry varies largely over space because of differentiated agro-environmental conditions [9]. In this regard, notions such as a 'sustainable rural development' should take account of the joint impact of different environmental factors on land degradation including — but not limited to-climate change, landscape transformations, soil erosion and water scarcity. Aspects related to human pressure (tourism concentration and infrastructure), crop intensification, water logging and soil compaction/salinization are also of primary importance $[49,52]$. From the positive perspective, geographic information tools with predictive capacity over time are increasingly required tools meeting the need of systemic evaluations of agro-ecosystem vulnerability to land degradation. Decision support systems were developed with the final aim to inform policies mitigating land degradation. The European Mediterranean Desertification and Land-Use (MEDALUS) information system described in Chapter 4 is an appropriate example [31,32]. This tool incorporates a module for quantification of the specific impact of land degradation on agricultural systems and rural districts. However, the approach proposed in the MEDALUS framework has revealed the following shortcomings: (i) Lack of a large-scale (e.g., national or continental), multi-temporal analysis of land vulnerability at high spatial resolution, and (ii) little 
attention to quantification of the monetary impacts of land degradation on agricultural systems (e.g., estimating the possible economic loss due to the increase of soil degradation in specialized, high value-added cropland).

Regarding the former statement, a large-scale, homogeneous assessment of the level of land vulnerability to degradation over time is a necessary policy tool, given the increasing human pressure (population growth, tourism concentration, increase of infrastructures, loss of fertile agricultural land, climate change) [52]. All the above-mentioned phenomena have shown a trend towards worse environmental conditions over the last 50 years. The lack of an appropriate, large-scale assessment of land degradation impact on specific crops, may explain the partial effectiveness of practical actions promoting soil conservation and mitigating land degradation, especially those incorporated in Local Action Plans $[36,38,43]$. In these regards, it was demonstrated how local stakeholders often lack precise economic information to calibrate more effective measures of soil conservation [17]. Regarding the latter statement, the scarcity of updatable and geo-referenced data sources with specific regards to some land dimensions, such as soil degradation or socioeconomic issues, seems to be a particularly relevant constraint to development of new methodologies, practical tools, and specific actions fighting against land degradation in Mediterranean rural areas [53].

Earlier research has stimulated the development of short-term predictive methodologies assessing specific dimensions of land degradation. In this regard, the main proposed tools are prediction of regional climate change, local-scale and regional-scale scenarios of land-use change and small-scale demographic projections [54]. However, integration of multiple scenarios deriving from different dimensions of land degradation need improvement and reliability of the resulting predictive models is quite low. Conditional projections—grounded on a 'what ... if' philosophy—were thus proposed in order to give a spatially relevant knowledge base for understanding of future dynamics, even without a precise confidence level. Purely deterministic schemes that simulate selected evolutionary paths, without giving an ex-ante probabilistic reliability, can be also used to corroborate or refuse conditional projections. In every case, projections based on elaboration of enough long time series of environmental variables are sufficient to provide useful information when integrated with multivariate exploratory statistical methodologies and metadata analysis when available [46].

\section{7. 'Zero Net' Land Degradation as a Policy Strategy}

Assuming the growing pressure on land from forestry, crop intensification and urban growth, the need for measurable policy targets emerged in the framework of the UNCCD. A new goal of sustainable development agreed at Rio +20 was the progressive decrease (or stability) of the level of land degradation at specific locations, a process that has been called as 'zero net Land Degradation' in the view of policies accomplishing land degradation neutrality. Neutrality is a condition achievable during a sufficiently long time period when non-degraded soil remains healthy and already degraded land is reestablished, reducing the net rate of productive land loss to zero (or close to zero). In 2012, UNCCD proposed an integrated set of interlinked goals packed into a comprehensive policy strategy against environmental degradation: (i) Zero net land degradation (no increase in vulnerability level of exposed land) by 2030, (ii) zero net forest degradation by 2030 and (iii) drought awareness policies applied in all drought-prone countries by 2020. Basic measures targeting zero net Land Degradation are: sustainable land processes counteracting degradation of fertile soils, stopping further processes of degradation and restoring (or rehabilitating) degraded land, improving traditional and community-based approaches and implementing a payment system for ecosystem services [55].

Assuming that the main causes of soil degradation and increasing land vulnerability to degradation in the Mediterranean basin are mainly human induced [56], a zero-net land degradation policy is particularly required in areas with critical climate conditions and declining ecosystem services, or with low resilience and capacity to recovery $[33,57-59]$. Socioeconomic resilience is defined as the ability of human institutions and local communities to adapt to change $[45,60]$. Since social changes and economic development indirectly stimulate a recovery of degraded environments in a resilience 
perspective, such vision recognizes that transformations are typical of human systems where every socioeconomic factor is continuously modified [17]. At the same time, the potential for socioeconomic growth and sustainable development depends on environmental and soil qualities, the ecological carrying capacity of the system as well as the adopted policies for land conservation. Policies addressing land conservation at wider spatial levels (e.g., regional scale) should contribute to rebalance urban, peri-urban and rural districts into a new, more sustainable and spatially balanced landscape 'continuum' from urban to rural areas, avoiding polarization in rich and poor places or segregation in economically dynamic or marginal locations.

An interdisciplinary framework is increasingly required to orient the relationship between rural systems and urban settlements in a truly sustainable vision, integrating eco-sustainable thinking and the more traditional socioeconomic dimension of growth [61]. In this regard, assessing socioeconomic and socio-ecological performances at local scale require innovative approaches and new indicators. For instance, assuming that diversification of a complex system is a process promoting resilience and consolidating ability to recovery to exogenous stresses, indexes of diversity and evenness of population structure are candidate indicators of resistance to external shocks in a given local community [62-64]. Assessing the spatial relationship between land vulnerability and resilience of local communities to exogenous stresses is therefore relevant to identification of local contexts responding more or less rapidly to policies against land degradation. For this purpose, it is essential to adopt predictive approaches that identify and understand the interacting dynamics of environmental and socioeconomic factors and give a correct formulation of short-term scenarios predicting the increase (or decrease) of land vulnerability to degradation [65]. These scenarios may specifically inform effective zero-net land degradation strategies at a local operational scale.

\section{Towards Integrated Operational Frameworks}

Preserving an active balance amongst human requirements and pressure on land resources through dedicated measures and incentives supporting local communities, is a characteristic of local contexts with a decline in land vulnerability to degradation and rising community resilience. This vision is coherent with a 'zero-net' land degradation strategy [17]. Based on the above assumption, integrated support systems informing policy decisions against land degradation should develop a functionally homogeneous framework constituted of structurally interacting, modular sets of methodologies and indicators. These modules should incorporate the following tools: (i) A time series analysis of the evolution of land vulnerability to degradation at significant locations were data are available for sufficiently long time intervals; (ii) conditional projections of short-term and medium-term land vulnerability to degradation integrating regional-scale outcomes of climate change models, land-use change scenarios and short-term, local-scale demographic projections; (iii) a geographic information system, working at a refined spatial detail and supporting stakeholders with basic and advanced information for decision; (iv) an econometric model of monetary costs of soil degradation and damages to specific crops in traditionally designated, affected areas.

A Decision Support System (DSS) can provide the necessary integration between the four modules through a user-friendly spatial query procedure meeting the user's needs. Two user's types will benefit from the implementation of such a tool: (i) Country-level and regional-level political actors, local administrators, and regional/local planners; (ii) managers of local production activities, including reclamation consortia, farmers' associations, cooperatives and large producers [48]. The absence of a bottom up participatory process to adopt the essential information among local communities and other actors can be also filled up using a detailed analysis of information from the system mentioned above [66]. A multi-dimensional DSS definitely benefits from continuous update and improvements in the available databases [13]. Re-analysis of micro-data from country (or supra-national) weather databases and improvement of regionalized estimates for specific variables (e.g., precipitation, average temperature, reference evapotranspiration) are finally needed to implement new indicators of climate aridity, drought and water balance relevant for analysis of land degradation neutrality [8]. 
Implementation of a soil data warehouse at supra-national scale via integration of different data sources and environmental statistics is a particularly appropriate knowledge base when implementing new indicators of soil degradation, especially in less investigated fields such as soil salinization, compaction, contamination and sealing, representing emerging (but relevant) phenomena of land degradation in the Mediterranean basin. Further efforts in acquisition and proper analysis of historical maps are required in the study of landscape transformations. A comprehensive analysis of human pressures requires a refined integration of data sources and available indicators from official statistics. The main processes of degradation triggered by anthropogenic factors (population density, tourism, infrastructures, wildfires), agricultural practices (irrigation, mechanization, soil compaction, soil loss, overgrazing) and industrialization should be described in a diachronic perspective [9,52], focusing on the relationship between agricultural policy, economic dynamics and environmental sustainability. The collected information may finally contribute to the creation of a refined assessment of land vulnerability to degradation. Multivariate statistics will contribute to reduce (or eliminate) redundancy and multi-collinearity among variables $[30,47]$.

\section{Conclusions}

The main target of policies against land degradation can be achieved by developing appropriate assessment frameworks and planning for sustainable land management [67-70]. Development of a predictive model estimating land vulnerability to degradation at specific locations may benefit from a set of literature indicators and new approaches producing local-scale land-use scenarios and population projections [71]. Future studies should integrate these components into a formal analysis of policy effectiveness, enhancing the practical experience collected in earlier research [41,49]. A permanent assessment of land degradation has practical effectiveness and provides useful tools to conservation policies [72]. Definition of target areas needing specific actions for biodiversity and landscape protection, and the dynamic evaluation of land degradation processes under global change are examples of relevant policy tools [73]. Identification of local districts with degraded land needing specific interventions to support biodiversity and landscape quality, makes a zero-net land degradation strategy more effective and spatially informed.

Author Contributions: Conceptualization, S.V. and G.E.; methodology, L.S.; investigation, L.S.; resources, G.E.; data curation, G.E.; writing — original draft preparation, S.V.; writing — review and editing, L.S.; visualization, R.S.; supervision, R.S.; project administration, R.S.; funding acquisition, R.S.

Funding: This research received no external funding.

Conflicts of Interest: The authors declare no conflict of interest.

\section{References}

1. Leigh, N.G.; Blakely, E.J. Planning Local Economic Development: Theory and Practice; SAGE: London, UK, 2016.

2. Murray, A.; Skene, K.; Haynes, K. The circular economy: An interdisciplinary exploration of the concept and application in a global context. J. Bus. Ethics 2017, 140, 369-380. [CrossRef]

3. Serra, P.; Vera, A.; Tulla, A.F.; Salvati, L. Beyond urban-rural dichotomy: exploring socioeconomic and land-use processes of change in Spain (1991-2011). Appl. Geogr. 2014, 55, 71-81. [CrossRef]

4. Zambon, I.; Sauri, D.; Serra, P.; Carlucci, M.; Salvati, L. Beyond the 'Mediterranean city': socioeconomic disparities and urban sprawl in three Southern European cities. Geogr. Ann. Ser. B Hum. Geogr. 2017, 99, 319-337. [CrossRef]

5. Zambon, I.; Benedetti, A.; Ferrara, C.; Salvati, L. Soil Matters? A Multivariate Analysis of Socioeconomic Constraints to Urban Expansion in Mediterranean Europe. Ecol. Econ. 2018, 146, 173-183. [CrossRef]

6. Alphan, H. Land use change and urbanisation of Adana, Turkey. Land Degrad. Dev. 2003, 14, 575-586. [CrossRef]

7. Salvati, L.; Petitta, M.; Ceccarelli, T.; Perini, L.; Di Battista, F.; Venezian Scarascia, M.E. Italy's renewable water resources as estimated on the basis of the monthly water balance. Irrig. Drain. 2008, 57, 507-515. [CrossRef] 
8. Salvati, L.; Zitti, M.; Ceccarelli, T.; Perini, L. Developing a synthetic index of land vulnerability to drought and desertification. Geogr. Res. 2009, 473, 280-291. [CrossRef]

9. Duvernoy, I.; Zambon, I.; Sateriano, A.; Salvati, L. Pictures from the other side of the fringe: Urban growth and peri-urban agriculture in a post-industrial city (Toulouse, France). J. Rural Stud. 2018, 57, 25-35. [CrossRef]

10. Salvati, L.; Zitti, M.; Ceccarelli, T. Integrating economic and environmental indicators in the assessment of desertification risk: A case study. Appl. Ecol. Environ. Res. 2008, 61, 129-138. [CrossRef]

11. Zitti, M.; Ferrara, C.; Perini, L.; Carlucci, M.; Salvati, L. Long-term Urban Growth and Land-use Efficiency in Southern Europe: Implications for Sustainable Land Management. Sustainability 2015, 7, 3359-3385. [CrossRef]

12. Pili, S.; Grigoriadis, E.; Carlucci, M.; Clemente, M.; Salvati, L. Towards Sustainable Growth? A Multi-criteria Assessment of (Changing) Urban Forms. Ecol. Indic. 2017, 76, 71-80. [CrossRef]

13. Salvati, L.; Serra, P. Estimating rapidity of change in complex urban systems: a multidimensional, local-scale approach. Geogr. Anal. 2016, 48, 132-156. [CrossRef]

14. Biasi, R.; Brunori, E.; Smiraglia, D.; Salvati, L. Linking traditional tree-crop landscapes and agro-biodiversity in Central Italy using a database of typical and traditional products: a multiple risk assessment through a data mining analysis. Biodivers. Conserv. 2015, 24, 3009-3031. [CrossRef]

15. Kizos, T.; Vasdeki, M.; Chatzikiriakou, C.; Dimitriou, D. 'For my children': Different functions of the agricultural landscape and attitudes of farmers on different areas of Greece towards small scale landscape change. Geogr. Tidsskr. Dan. J. Geogr. 2011, 111, 117-130. [CrossRef]

16. Costantini, E.; Urbano, F.; Bonati, G.; Nino, P.; Fais, A. Atlante Nazionale delle Aree a rischio di Desertificazione; Consiglio per la Ricerca e la Sperimentazione in Agricoltura, Istituto sperimentale per lo studio e la difesa del suolo, Centro Nazionale di Cartografia Pedologica: Rome, Italy, 2007.

17. Kelly, C.; Ferrara, A.; Wilson, G.A.; Ripullone, F.; Nolè, A.; Harmer, N.; Salvati, L. Community resilience and land degradation in forest and shrubland socio-ecological systems: Evidence in Gorgoglione, Basilicata, Italy. Land Use Policy 2015, 46, 11-20. [CrossRef]

18. Antrop, M. Landscape change and the urbanization process in Europe. Landsc. Urban Plan. 2004, 67, 9-26. [CrossRef]

19. Carlucci, M.; Grigoriadis, E.; Rontos, K.; Salvati, L. Revisiting a Hegemonic Concept: Long-term 'Mediterranean Urbanization' in between city re-polarization and metropolitan decline. Appl. Spat. Anal. Policy 2017, 10, 347-362. [CrossRef]

20. Menichini, E. La Desertificazione dei Suoli; Green Challenge: Pisa, Italy, 2008.

21. Polyzos, S.; Christopoulou, O.; Minetos, D.; Leal Filho, W. An overview of urban-rural land use interactions in Greece. Int. J. Agric. Resour. Gov. Ecol. 2008, 7, 276-296. [CrossRef]

22. Francaviglia, R. La Desertificazione; Consiglio per la Ricerca e la Sperimentazione in agricoltura, Centro di Ricerca per lo Studio delle Relazioni tra Pianta e Suolo, Osservatorio Nazionale Pedologico e per la qualità del Suolo: Rome, Italy, 2011.

23. Colantoni, A.; Monarca, D.; Laurendi, V.; Villarini, M.; Gambella, F.; Cecchini, M. Smart Machines, Remote Sensing, Precision Farming, Processes, Mechatronic, Materials and Policies for Safety and Health Aspects. Agriculture 2018, 8, 47. [CrossRef]

24. Marucci, A.; Colantoni, A.; Zambon, I.; Egidi, G. Precision farming in hilly areas: The use of network RTK in GNSS technology. Agriculture 2017, 7, 60. [CrossRef]

25. Zambon, I.; Delfanti, L.; Marucci, A.; Bedini, R.; Bessone, W.; Cecchini, M.; Monarca, D. Identification of optimal mechanization processes for harvesting Hazelnuts based on geospatial technologies in Sicily (Southern Italy). Agriculture 2017, 7, 56. [CrossRef]

26. Ceccarelli, T.; Bajocco, S.; Perini, L.; Salvati, L. Urbanisation and Land Take of High-Quality Agricultural Soils - Exploring Long-term Land Use Changes and Land Capability in Northern Italy. Int. J. Environ. Res. 2014, 8, 181-192.

27. Barbero-Sierra, C.; Marques, M.J.; Ruíz-Pérez, M. The case of urban sprawl in Spain as an active and irreversible driving force for desertification. J. Arid Environ. 2013, 90, 95-102. [CrossRef]

28. Aru, A. Erosione e desertificazione. Boll. Sco. It. Sc. Suolo 2002, 51, 769-783.

29. Ferrara, A.; Bellotti, A.; De Natale, F.; Faretta, N.; Mancino, G.; Taberner, M. MEDALUS III-Identification and Assesment of Environmental Sensitive Areas by Remote Sensing 2nd Annual Report; King's College: London, UK, 1997. 
30. Ferrara, A. Expert System for Evaluating the Environmental Sensitivity Index (ESI) of a Local Area. In DIS4ME: Desertification Indicator System for Mediterranean Europe; Jane, B., Ed.; Bruxelles, Belgium, 2005. Available online: http://www.kcl.ac.uk/projects/desertlinks (accessed on 11 October 2019).

31. Kosmas, C.; Ferrara, A.; Briassoulis, H.; Imeson, A. Methodology for mapping Environmentally Sensitive Areas (ESAs) to Desertification. In The Medalus Project Mediterranean Desertification and Land Use. Manual on Key Indicators of Desertification and Mapping Environmentally Sensitive Areas to Desertification; Kosmas, C., Kirkby, M., Geeson, N., Eds.; European Union: Brussels, Belgium, 1999.

32. Kosmas, C.; Kirkby, M.; Geeson, N. The MEDALUS Project. Mediterranean Desertification and Land Use. Manual on Key Indicators of Desertification and Mapping Environmentally Sensitive Areas to Desertification; European Union: Brussels, Belgium, 1999.

33. Salvati, L.; Mavrakis, A.; Colantoni, A.; Mancino, G.; Ferrara, A. Complex Adaptive Systems, soil degradation and land sensitivity to desertification: A multivariate assessment of Italian agro-forest landscape. Sci. Total Environ. 2015, 521, 235-245. [CrossRef] [PubMed]

34. Salvati, L.; Zitti, M.; Perini, L. Fifty Years on: Long-term Patterns of Land Sensitivity to Desertification in Italy. Land Degrad. Dev. 2016, 272, 97-107. [CrossRef]

35. Colantoni, A.; Delfanti, L.; Recanatesi, F.; Tolli, M.; Lord, R. Land use planning for utilizing biomass residues in Tuscia Romana (central Italy): Preliminary results of a multi criteria analysis to create an agro-energy district. Land Use Policy 2016, 50, 125-133. [CrossRef]

36. Colombo, V.; Zucca, C.; Enne, G. Indicatori di Desertificazione Approccio Integrato e Supporto alle Decisioni; ENEA Ente per le Nuove tecnologie l'Energia e l'Ambiente: Sassari, Italy, 2006.

37. Monarca, D.; Cecchini, M.; Guerrieri, M.; Colantoni, A. Conventional and alternative use of biomasses derived by hazelnut cultivation and processing. In Proceedings of the VII International Congress on Hazelnut 845, Viterbo, Italy, 23-27 June; 2008; pp. 627-634.

38. Luise, A.; Viti, S.; Giordano, F.; Marra Campanale, R. Indicatori di Desertificazione Aspetti Generali, Metodologie di Mappatura Delle Arre Sensibili, Indici di Aridità e di Siccità, Caratteristiche Socio-Economiche; Rapporto Tecnico Realizzato Nell'ambito del Progetto DesertNet: Rome, Italy, 2004.

39. Brandt, J.; Geeson, N. Desertification and indicators system for Mediterranean Europe LUCINDA; LUCINDA A(2): Wageningen, the Netherlands, 2008.

40. Kosmas, C.; Kairis, O.; Karavitis, C.; Acikalin, S.; Alcalá, M.; Alfama, P.; Atlhopheng, J.; Barrera, J.; Belgacem, A.; Solé-Benet, A.; et al. An exploratory analysis of land abandonment drivers in areas prone to desertification. Catena 2015, 128, 252-261. [CrossRef]

41. Kosmas, C.; Kairis, O.; Karavitis, C.; Ritsema, C.; Salvati, L.; Acikalin, S.; Alcalá, M.; Alfama, P.; Atlhopheng, J.; Barrera, J.; et al. Evaluation and Selection of Indicators for Land Degradation and Desertification Monitoring: Methodological Approach. Environ. Manag. 2013, 545, 951-970. [CrossRef]

42. Kosmas, C.; Danalatos, N.; Cammeraat, L.H.; Chabart, M.; Diamantopoulo, J.; Farand, R.; Gutierrez, L.; Jacob, A.; Marques, H.; Martinez-Fernandez, J.; et al. The effect of land use on runoff and soil erosion rates under Mediterranean conditions. Catena 1997, 29, 45-59. [CrossRef]

43. Montanarella, L.; Paracchini, R.; Rusco, E. Programma d'Azione per la Lotta alla Siccità e alla Desertificazione, Indicazione delle aree Vulnerabili in Puglia; Regione Puglia, Settore Programmazione Ufficio Informatico e Servizio Cartografico: Bari, Italy, 2000.

44. European Environment Agency (EEA). State of the Environment Report No 1/2005. 2005. Available online: http://www.eea.europa.eu/publications/state-of-environment- (accessed on 10 November 2019).

45. Galston, W.A.; Baehler, K.J. Rural Development in the United States: Connecting Theory, Practice, and Possibilities; Island Press: Washington, DC, USA, 1995.

46. Kairis, O.; Kosmas, C.; Karavitis, C.; Ritsema, C.; Salvati, L.; Acikalin, S.; Alcalá, M.; Alfama, P.; Atlhopheng, J.; Barrera, J.; et al. Evaluation and Selection of Indicators for Land Degradation and Desertification Monitoring: Types of Degradation, Causes, and Implications for Management. Environ. Manag. 2013, 545, 971-982. [CrossRef] [PubMed]

47. Briassoulis, H. Combating Land Degradation and Desertification: The Land-Use Planning Quandary. Land 2019, 8, 27. [CrossRef]

48. Recanatesi, F.; Clemente, M.; Grigoriadis, S.; Ranalli, F.; Zitti, M.; Salvati, L. A fifty-years sustainability assessment of Italian Agro-forest Districts. Sustainability 2016, 8, 32. [CrossRef] 
49. Kairis, O.; Karavitis, C.; Kounalaki, A.; Salvati, L.; Kosmas, C. The effect of land management practices on soil erosion and land desertification in an olive grove. Soil Use Manag. 2013, 294, 597-606. [CrossRef]

50. Colantoni, A.; Grigoriadis, E.; Sateriano, A.; Venanzoni, G.; Salvati, L. Cities as selective land predators? A Lesson on Urban Growth, (Un)effective planning and Sprawl Containment. Sci. Total Environ. 2016, 545-546, 329-339. [CrossRef]

51. Costa, F.; Noble, A.G.; Pendleton, G. Evolving planning systems in Madrid, Rome, and Athens. Geojournal 1991, 24, 293-303. [CrossRef]

52. Cuadrado-Ciuraneta, S.; Durà-Guimerà, A.; Salvati, L. Not only tourism: unravelling suburbanization, second-home expansion and "rural" sprawl in Catalonia, Spain. Urban Geogr. 2017, 381, 66-89. [CrossRef]

53. Salvati, L.; Perini, L.; Ceccarelli, T.; Zitti, M.; Bajocco, S. Towards a process-based evaluation of soil vulnerability to degradation: A spatio-temporal approach in Italy. Ecol. Indic. 2011, 11, 1216-1227. [CrossRef]

54. Grekousis, G.; Manetos, P.; Photis, Y.N. Modeling urban evolution using neural networks, fuzzy logic and GIS: The case of the Athens metropolitan area. Cities 2013, 30, 193-203. [CrossRef]

55. Imeson, A. Desertification, Land Degradation and Sustainability; John Wiley Sons: New Jersey, NJ, USA, 2012.

56. Feoli, E.; Giacomich, P.; Mignozzi, K.; Oztürk, M.; Scimone, M. Monitoring desertification risk with an index integrating climatic and remotely sensed data: an example from the coastal area of Turkey. Manag. Environ. Qual. Int. J. 2003, 14, 10-21. [CrossRef]

57. Simeonakis, E.; Calvo-Cases, A.; Arnau-Rosalen, E. Land use change and land degradation in southeastern Mediterranean Spain. Environ. Manag. 2007, 40, 80-94. [CrossRef] [PubMed]

58. Contador, J.L.; Schnabel, S.; Gutiérrez, A.G.; Fernández, M.P. Mapping sensitivity to land degradation in Extremadura. SW Spain. Land Degrad. Dev. 2009, 20, 129-144. [CrossRef]

59. Ferrara, A.; Salvati, L.; Sabbi, A.; Colantoni, A. Soil resources, land cover changes and rural areas: Towards a spatial mismatch? Sci. Total Environ. 2014, 478, 116-122. [CrossRef] [PubMed]

60. Haynes, R.W.; Graham, R.T.; Quigley, T.M. A Framework for Ecosystem Management in the Interior Columbia Basin and Portions of the Klamath and Great Basins; U.S. Department of Agriculture, Forest Service, Pacific Northwest Research Station: Washington, DC, USA, 1996; p. 47.

61. Moretti, V.; Sateriano, A.; Zitti, M.; Salvati, L. Towards 'Mediterranean' Entropy? A Commentary on Urban Growth, Fringe Land, Demography and Economic Transition in Southern Europe. Int. J. Humanit. Soc. Sci. 2015, 5, 97-103.

62. Pielou, E.C. Shannon's formula as a measure of specific diversity: its use and misuse. Am. Nat. 1966, 100, 463-465. [CrossRef]

63. Shannon, C.E.; Weaver, W. The Mathematical Theory of Communication; The University of Illinois Press: Urbana, IL, USA, 1949.

64. Simpson, E.H. Measurement of diversity. Nature 1949, 163, 688. [CrossRef]

65. Ferrara, A. I Sistemi an Indicatori Chiave nella Valutazione della Vulnerabilità Ambientale alla Desertificazione; Corona, P., Iovino, F., Maetzke, F., Marchetti, M., Menguzzato, G., Nocentini, S., Eds.; Portoghesi (a cura di), Foreste Ricerca Cultura, Accademia Italiana di Scienze Forestali: Rome, Italy, 2005.

66. Plaisant, A.; Mastinu, M.; Sini, D. Risk Prevention and Management. A Multi-actor and Knowledge-Based Approach in Low Density Territories. In International Conference on Computational Science and Its Applications; Springer: Cham, Switzerland, 2017; pp. 252-265.

67. Batáry, P.; Dicks, L.V.; Kleijn, D.; Sutherland, W.J. The role of agri-environment schemes in conservation and environmental management. Conserv. Biol. 2015, 29, 1006-1016. [CrossRef]

68. Corona, P.; Ferrari, B.; Iovino, F.; La Mantia, T.; Barbati, A. Rimboscamenti e lotta alla Desertificazione in Italia; Aracne editrice: Rome, Italy, 2009.

69. Geeson, N.A.; Brandt, C.J.; Thomes, J.B. Mediterranean Desertification Environments in Europe. The Desertification Context; John Wiley Sons: Chichester, UK, 2002.

70. Salvati, L.; Carlucci, M. Zero Net Land Degradation in Italy: The role of socioeconomic and agro-forest factors. J. Environ. Manag. 2014, 145, 299-306. [CrossRef]

71. Salvati, L.; Biasi, R.; Carlucci, M.; Ferrara, A. Forest transition and urban growth: Exploring latent dynamics (1936-2006) in Rome, Italy, using a geographically weighted regression and implications for coastal forest conservation. Rend. Lincei 2015, 577-585. [CrossRef] 
72. Biasi, R.; Barbera, G.; Marino, D.; Brunori, E.; Nieddu, G. Viticulture as crucial cropping system for counteracting the desertification of coastal land. Acta Hortic. 2012, 931, 71-78. [CrossRef]

73. Biasi, R.; Botti, F.; Barbera, G.; Cullotta, S. The role of Mediterranean fruit tree orchards and vineyards in maintaining the traditional agricultural landscape. Acta Hortic. 2012, 940, 79-88. [CrossRef]

(C) 2019 by the authors. Licensee MDPI, Basel, Switzerland. This article is an open access article distributed under the terms and conditions of the Creative Commons Attribution (CC BY) license (http://creativecommons.org/licenses/by/4.0/). 